\title{
ÍNDIOS NO SEMIÁRIDO NORDESTINO: (re)conhecendo sociodiversidades
}

RESUMO: Os povos indígenas no Nordeste questionam a produção historiográfica que até recentemente omitiu, ignorou ou relegou os índios vistos genericamente em um passado colonial distante. As experiências vivenciadas pelos indígenas no Semiárido nordestino constituem-se, portanto, em um desafio para reflexões sobre a compreensão dos processos históricos que resultam nas mobilizações sociopolíticas atuais em defesa da garantia dos direitos adquiridos e na luta por novas conquistas. É necessário pensar os indígenas no Semiárido nordestino na perspectiva de uma História Ambiental em um exercício de pesquisas, estudos e reflexões para estabelecer as relações entre os índios e as condições de vida no Ambiente onde habitam. Assim, pode-se reconhecer as sociodiversidades indígenas e contribuir para discussões na perspectiva histórica que evidenciem as relações de poder, o acesso, a utilização e significados dos recursos naturais pelos povos indígenas.

PALAVRAS-CHAVE: Índios, Nordeste, História Ambiental, Semiárido.

\section{Indians in the Northeast Semiarid: (Re)knowing sociodiversities}

\begin{abstract}
The indigenous peoples in the Northeast of Brazil question the historiographical production that until recently omitted, ignored or relegated the generic Indians to a distant colonial past. The experiences lived by the natives in the northeastern semi-arid are, therefore, a challenge for reflections on the understanding of the processes historical changes that result in the current sociopolitical mobilizations by the claims, conquests and guarantees of rights. It is necessary to think of the natives in the northeastern Semi-arid region in the perspective of a Environmental History in an exercise of research, studies and reflections to establish the relations between the Indians and the conditions of life in the environment where they live. Recognizing indigenous sociodiversities and contributing to discussions in the historical perspective that demonstrate the power relations, access, use and meanings of natural resources by indigenous peoples.
\end{abstract}

KEYWORDS: Indians, Northeast of Brazil, Environmental History, Semiarid.

\section{Índices en el semiárido del norte-medio: (Re)conociendo sociodiversidades}

RESUMEN: Los pueblos indígenas del Noreste critican la producción historiográfica que hasta hace poco tiempo les omitió, ignoró o relegó, viéndoles genéricamente en un pasado colonial lejano. Las experiencias vividas por los indígenas del Semiárido nordestino se constituyen, por lo tanto, en un desafío para las reflexiones relativas al entendimiento de los procesos históricos que resultan en las movilizaciones sociopolíticas actuales en defensa de los derechos conquistados y en la lucha por nuevas conquistas. Es necesario pensar los indígenas en el Semiárido nordestino desde la perspectiva de la Historia Ambiental en un ejercicio de investigación, estudios y reflexiones para establecer las relaciones entre ellos y las condiciones de vida en el ambiente donde viven. De esa manera, se puede reconocer las sociodiversidades indígenas y contribuir para las discusiones desde la perspectiva histórica que pongan en evidencia las relaciones de poder, el acceso, el uso y los significados de los recursos naturales de dichos pueblos.

PALABRAS CLAVE: Indígenas de Nordeste, Historia Ambiental, Semiárido.

*Professor Titular de História do Colégio de Aplicação da Universidade Federal de Pernambuco. Pós-Doutor pela Universidade Federal do Rio de Janeiro. É professor no curso de Mestrado Profissional em História (PROFHISTÓRIA) na Universidade Federal de Pernambuco e no curso de Mestrado em História na Universidade Federal de Campina Grande/PB. Contato: Av. da Arquitetura s/n, Cidade Universitária, CEP:50.740-550, Recife- PE, Brasil. E-mail: edson.edsilva@hotmail.com 
A uma civilização que elimina as diferenças, a

História deve restituir o sentido perdido das particularidades.

Philippe Aries

\section{Reconhecer as diferenças, (re)conhecer as sociodiversidades indígenas}

Ainda que a ideia de "civilização", afirmada pelo medievalista francês Philippe Aries, seja questionável enquanto um conceito etnocêntrico e eurocêntrico, as frases acima, com a quais o autor concluiu em 1949 seu livro O tempo da História ${ }^{1}$, constituem uma crítica velada à uniformização pautada pela modernidade com as supressões das expressões socioculturais regionais e locais. O reconhecido historiador escreveu no período pós Segunda Guerra, quando o mundo ainda perplexo procurava curar as feridas e buscava explicações para compreender a "barbárie" que a humanidade vivenciara havia poucos anos.

As ideias de "civilização", "evolução" e "progresso" para pensar a história da humanidade foram elaboradas como estudo científico no século XIX. Em 1870, o advogado norte-americano Lewis Morgan publicou o livro A sociedade antiga, traduzido para o português como A sociedade primitiva, em que classificou os grupos humanos a partir de três categorias: selvagens, bárbaros e civilizados. Eram classificações para explicar o "desenvolvimento" ou o "progresso" dos povos, e o que definiria uma civilização seria a existência do Estado, a família monogâmica e a propriedade (privada).

Segundo ainda essa concepção, uma civilização detinha conhecimentos, organização e inovações tecnológicas, o que lhe diferenciava dos estágios da selvageria e barbárie. Essas ideias baseadas no evolucionismo eram profundamente etnocêntricas, pois julgavam outros povos a partir de alguns poucos valores considerados superiores, influenciando o pensamento sobre os povos não europeus. Os indígenas ${ }^{2}$ na América, os povos africanos e asiáticos passaram a ser vistos como primitivos, atrasados e inferiores.

A ideia de "civilização" da louvada Ciência e do exaltado progresso humano da segunda metade do século XIX foi profundamente abalada e questionada na primeira metade do século XX, quando a humanidade vivenciou a "barbárie" das duas grandes guerras mundiais que destroçou povos, destruiu cidades, matando milhares de pessoas. A fundação da Organização das Nações Unidas/ONU, após a 2ª Guerra Mundial, em fins de 1945, foi uma resposta, um acordo entre os países de todos os continentes como forma de evitar novas guerras mundiais. ${ }^{3}$ 
O antropólogo francês Claude Lévi-Strauss, entre meados e finais dos anos 1939, lecionou Sociologia na USP e nas férias realizou pesquisas junto aos então índios "isolados", habitantes na época do chamado Brasil Central. Durante a Segunda Guerra, o antropólogo exilou-se nos Estados Unidos e em 1952, com a criação do UNESCO, assumiu o cargo de Secretário Geral desse organismo da ONU. No mesmo ano, foi publicado em Paris pela UNESCO o texto Raça e História, em que Lévi-Strauss, visivelmente influenciado por suas experiências com os povos indígenas no Brasil, tratou da "contribuição das raças humanas para a civilização mundial". 4

O nomeado "panfleto", foi também considerado um manifesto antirracista com grandes repercussões por relativizar as concepções etnocêntricas de progresso e Civilização Ocidental. E ao afirmar a existência da "diversidade de culturas", reconheceu a riqueza das sociodiversidades humanas expressa pelos conhecimentos de diferentes povos nas várias regiões da Terra, enfatizou a necessidade das contribuições entre as "culturas" e a convivência respeitosa como vital para o próprio futuro da humanidade.

A Convenção 169 sobre Povos Indígenas e Tribais publicada Organização Internacional do Trabalho/OIT, publicada em $1989^{5}$, da qual o Brasil é signatário afirmou que:

Art. 3: Os povos indígenas e tribais deverão gozar plenamente dos direitos humanos e liberdades fundamentais, sem obstáculos nem discriminação. As disposições desta Convenção serão aplicadas sem discriminação aos homens e mulheres desses povos; Art. 5: deverão ser reconhecidos e protegidos os valores e práticas sociais, culturais religiosos e espirituais próprios dos povos mencionados e dever-se-á levar na devida consideração a natureza dos problemas que lhes sejam apresentados, tanto coletiva como individualmente;

Art.14: Dever-se-á reconhecer aos povos interessados os direitos de propriedade e de posse sobre as terras que tradicionalmente ocupam. Além disso, nos casos apropriados, deverão ser adotadas medidas para salvaguardar o direito dos povos interessados de utilizar terras que não estejam exclusivamente ocupadas por eles, mas às quais, tradicionalmente, tenham tido acesso para suas atividades tradicionais e de subsistência. Nesse particular, deverá ser dada especial atenção à situação dos povos nômades e dos agricultores itinerantes.

Mesmo que o texto da Convenção 169 tenha utilizado a expressão "tribais" em uma concepção etnocêntrica herdada do Século XIX, o documento representa a definição de novas relações entre os grupos étnicos e os Estados nacionais. Sendo, portanto, um instrumento jurídico e político a ser acionado pelos povos autóctones no respeito e defesa de seus interesses.

Na Sessão Plenária realizada em setembro de 2007, a Assembleia Geral da ONU aprovou a Declaração das Nações Unidas sobre os Direitos dos Povos Indígenas ${ }^{6}$, na qual o preâmbulo afirma que os Estados nacionais estavam: 
Reconhecendo a necessidade urgente de respeitar e promover os direitos intrínsecos dos povos indígenas, que derivam de suas estruturas políticas, econômicas e sociais e de suas culturas, de suas tradições espirituais, de sua história e de sua concepção da vida, especialmente os direitos às suas terras, territórios e recursos.

Passados mais de 70 anos da Segunda Guerra, os chamados "povos originários" nos vários continentes e no Brasil, os denominados povos indígenas, continuam mobilizados para o reconhecimento, conquista e garantia de seus direitos, sobretudo as terras onde habitam. Diante do colonialismo dos Estados nacionais, as oligarquias invasoras em terras habitadas pelos índios, os grandes projetos e empreendimentos privados e governamentais que em nome do progresso são instalados nos territórios indígenas.

O Censo IBGE/2010 contabilizou quase 900 mil índios no Brasil, em uma diversidade de 305 povos falantes de 274 línguas. São desde povos numerosos, ou os com o menor número de indivíduos, habitando nas fronteiras do Brasil e em outros países vizinhos, nas florestas da região amazônica, no Xingu, ou nos cerrados, nos pampas gaúchos, no litoral e nos sertões nordestinos. Como também foi registrado mais de $36 \%$ de índios habitando em contextos urbanos, seja pelo avanço das cidades sobre as áreas indígenas, seja pelas migrações dos índios para os centros urbanos em razão de expulsões ou falta de terras para trabalharem em seus locais de origens, ou ainda pela busca de melhores condições de vida.

O Censo qualificou a pesquisa em relação aos índios, quando introduziu questões referentes ao pertencimento étnico, a língua falada e o domicílio. Os resultados censitários caracterizaram três situações sobre os indígenas no Nordeste: a primeira correspondendo às populações habitando em terras indígenas; a segunda, os índios vivendo nas capitais, nos grandes centros em áreas urbanas próximas às aldeias, mantendo constantes laços sociais e afetivos com estas; e a terceira as "pessoas que autodeclaram indígenas, mas cuja sociabilidade não está primordialmente dirigida para a aldeia, nem para a cidade".7

Ainda segundo o Censo IBGE/2010, em Pernambuco foram contabilizadas 60.995 “pessoas indígenas", das quais 13.414 estavam "fora de terras indígenas" e 3.665 no Recife ${ }^{8}$. Portanto, os resultados do Censo apresentaram uma situação até então supostamente desconhecida: a significativa presença de indivíduos e famílias indígenas em contextos urbanos, em sua maioria nas periferias e enfrentando as difíceis condições de moradia comuns nesses espaços. As designações "índios urbanos", "desaldeados" ou "índios na cidade" tem gerado um mal-estar entre os indígenas, existindo o risco de naturalizar-se uma situação, exigindo a necessidade de políticas públicas específicas e diferenciadas, que são falhas, descontínuas e precárias mesmo para os índios habitando nas aldeias. 
Além de um olhar diferenciado daquelas imagens que vinculam os indígenas à floresta, às áreas rurais no interior do pais, a presença de indígenas em contextos urbanos, a exemplo do Recife, significa as possibilidades de termos um/a vizinho/a, um/a estudante, um/a trabalhador/a indígena convivendo conosco. Bem como também exige a efetivação de medidas no âmbito educacional (re)conhendo essas sociodiversidades, a exemplo da Lei $\mathrm{n}^{\circ}$ 11.645/2008 que determinou a inclusão da história e culturas indígenas nos currículos da Educação Básica.

A propósito do tema do dossiê em que está sendo publicado o presente texto, os povos indígenas são parte significativa das "questões socialmente vivas", desafiando a produção historiográfica, que até recentemente omitiu, ignorou ou relegou os índios a um passado colonial distante. Em se tratando dos índios no Nordeste, estes foram ainda considerados exterminados, desaparecidos, negados com o mito da mestiçagem ou pela suposta aculturação. A atualidade dos povos indígenas no Nordeste e as pesquisas recentes ${ }^{9}$ questionam essas explicações e a produção historiográfica a respeito das populações indígenas, sobretudo aquelas habitando no Semiárido nordestino.

\section{Por uma história ambiental indígena no Semiárido}

No Nordeste, os habitantes dos lugares onde existiram antigos aldeamentos foram chamados de "caboclos", condição essa muitas vezes assumida pelos indígenas para esconder a identidade étnica diante das inúmeras perseguições de invasores das terras habitadas pelos indígenas. A essas populações foram dedicados estudos sobre seus hábitos e costumes, considerados exóticos, suas danças e "manifestações folclóricas" pensadas em vias de extinção. Escritores renomados, intelectuais e pesquisadores como Gilberto Freyre, Raquel de Queiroz, Câmara Cascudo, José Lins do Rego, Graciliano Ramos, Jorge Amado, só para citar alguns dentre os nomes mais conhecidos, quando se referiram aos índios se remeteram a um passado idílico, omitindo a continuidade da presença de diversos povos indígenas no Nordeste brasileiro. $^{10}$

Ou, ainda, antropólogos como Darcy Ribeiro que afirmou o desparecimento dos índios no Nordeste. Esse renomado antropólogo foi autor de uma vastíssima obra, dentre seus livros o mais conhecido é Os índios e a civilização. A primeira edição desse livro com o subtítulo "a integração das populações indígenas no Brasil moderno”, foi publicada em 1970. Nesse livro o autor fez uma retomada histórica sobre os processos de guerras, violências e invasões dos territórios indígenas em todas as regiões do nosso país. Em nota na "Introdução" dessa 
publicação, Ribeiro afirmou que o livro era resultado do relatório de pesquisas que realizara desde 1952, parcialmente publicadas em 1958 e com versões de alguns dos capítulos divulgadas em revistas nacionais e internacionais nos anos seguintes. Darcy Ribeiro foi funcionário do Serviço de Proteção aos Índios/SPI, órgão estatal cuja concepção e atuação fundamentava-se nas ideias do Positivismo, que pensava os índios como na infância da humanidade, como "primitivos" e, portanto, fora da chamada civilização tecnológica.

O antropólogo ao pesquisar e escrever na década de 1950 foi bastante influenciado pelas ideias do período pós-Segunda Guerra Mundial. Era então a partir desse contexto de superação da "barbárie" pela modernidade da "civilização", que Darcy Ribeiro denunciou as violências da colonização portuguesa, do Estado brasileiro, e pensou sobre os índios na História do nosso país. São bastante conhecidas as suas afirmações do genocídio e etnocídio sobre a história dos povos indígenas no Brasil, ou seja, as ideias do desaparecimento e o extermínio de povos e culturas indígenas, tão enfatizadas por Darcy Ribeiro.

O autor também advogou as "etapas da integração", para os povos indígenas existentes nas áreas mais antigas da colonização portuguesa, a exemplo do Nordeste. As categorias de índios "integrados" e de "grau de integração na sociedade nacional" foram atribuídas aos grupos indígenas que se encontravam no século XX "ilhados em meio à população nacional" ${ }^{11}$, como também a ideia da aculturação e assimilação dos índios com a incorporação na chamada sociedade nacional.

Os méritos de Darcy Ribeiro decorrem de ter sido o primeiro autor que discutiu o "problema indígena" ("problema" para quem?!) de uma forma ampla, e por sua explícita posição política em denunciar as opressões sobre os índios na História do Brasil, o que tornou as ideias do antropólogo bastante conhecidas. Apesar de suas ideias superadas sobre o extermínio dos povos indígenas como "vítimas" do inevitável "progresso", o livro Os índios e a civilização, com várias edições, por sua quantidade de informações e dados continua sendo uma leitura necessária e até obrigatória para uma visão global sobre os povos indígenas no Brasil. As ideias desse livro a respeito dos índios em muito influenciaram a visão de outros estudiosos e o senso comum a respeito dos chamados "índios" e as suas expressões socioculturais, sobre o destino e o futuro dos povos indígenas em nosso país.

A perspectiva de Darcy Ribeiro não mudou, mesmo em outro contexto sociopolítico e com novas abordagens antropológicas sobre os índios no Nordeste ${ }^{12}$, como observado no texto “Os índios e nós” publicado na coletânea Sobre o óbvio, organizada pelo autor em 1986. No referido texto, Ribeiro afirmou realizar uma avaliação baseada em dados de 1956. Sobre a “integração" dos grupos indígenas o antropólogo escreveu: 
Em lugar de assimilação o que ocorre é o é o seu desaparecimento por desgaste etnocida ou por extermínio genocida, ou sua sobrevivência como grupos 'integrados' a vida regional, na qualidade de contingentes cada vez menos diferenciados da gente do seu contexto mas que continuam, apesar disso, se identificando e sendo identificados como indígenas. ${ }^{13}$

A ideia de um Brasil moderno formado por uma macroetnia, foi retomada e defendida pelo antropólogo em estudos posteriores, a exemplo do livro $O$ povo brasileiro, segundo o próprio Darcy Ribeiro, a síntese de sua "teoria de Brasil". O livro foi publicado em 1995, quando o autor se encontrava-se gravemente enfermo, de uma doença terminal. Na sua perspectiva, os grupos indígenas, mesmo aqueles considerados "isolados", enquanto microetnias em nada influenciariam a configuração do país, muito menos os “integrados”!

Os povos indígenas no Semiárido nordestino retomaram suas mobilizações sociopolíticas desde as primeiras décadas do século XX, conquistando o reconhecimento do Estado brasileiro com a instalação de postos indígenas pelo Serviço de Proteção aos Índios (SPI), incialmente em 1924 entre os Fulni-ô em Águas Belas (PE). Embora a atuação desse órgão governamental tenha sido muito assistencialista, sem garantir as terras aos indígenas, mantendo o regime de povos tutelados e coibindo as expressões socioculturais indígenas. Mas, a instalação do citado Posto Indígena (PI), impulsionou a formação de uma articulação entre outros povos indígenas em Pernambuco como os Pankararu (Tacaratu), os Atikum e os Pankará (Floresta) e os Xukuru (Pesqueira) que até meados dos anos 1950 reivindicaram e foram atendidos com a instalação de PIs nas terras onde habitavam. ${ }^{14} \mathrm{Com}$ isso, os indígenas no Nordeste vivenciaram processos históricos que resultaram nas mobilizações sociopolíticas atuais pelas reivindicações, conquistas e garantias de seus direitos.

As violências da ocupação colonial portuguesa foram tamanhas que, na atualidade, são registrados poucos povos indígenas habitantes no litoral. Embora as invasões com as fazendas de gado no Sertão (Semiárido) nordestino também tenham ocorrido por meio de guerras e conflitos contra os nativos, possivelmente a dimensão espacial favoreceu a dispersão e resistência de um considerável número de grupos indígenas, como é expresso pelos diversos povos conhecidos no interior do atual Nordeste brasileiro.

Nas regiões Agreste e Sertão, atualmente denominada de Semiárido nordestino, as disputas pelos espaços úmidos e pelas fontes de água sempre foram intensas. O Semiárido é cenário de muitos conflitos entre os índios, seus primeiros moradores, e os fazendeiros invasores, tratando-se de uma região que recebe pequena quantidade de chuvas, caracterizada pelos solos rasos e não raro pedregosos, vegetação da caatinga e rios intermitentes, onde ocorrem longas estiagens ou secas periódicas, muitas vezes calamitosas, agravando a qualidade dos solos e o aproveitamento dos recursos naturais disponíveis. 
O Semiárido brasileiro, considerado a região mais populosa do mundo em ambiente com essas características, foi oficialmente redefinido pelo Ministério da Integração Nacional em 2005. Compreendendo 1.113 municípios nos estados nordestinos, com exceção do Maranhão, estende-se até o Norte de Minas Gerais. O Semiárido foi caracterizado como a região com a "precipitação pluviométrica média anual inferior a 800 milímetros" 15 .

E ainda,

As regiões semiáridas são caracterizadas, de modo geral, pela aridez do clima, pela deficiência hídrica com imprevisibilidade das precipitações pluviométricas e pela presença de solos pobres em matéria orgânica. O prolongado período seco anual eleva a temperatura local, caracterizando a aridez sazonal. Conforme essa definição, o grau de aridez de uma região depende da quantidade de água advinda da chuva (precipitação) e da temperatura que influencia a perda de água por meio da evapotranspiração potencial. ${ }^{16}$

Os brejos são áreas úmidas existentes no Semiárido com cobertura vegetal densa de espécies endêmicas e também da Mata Atlântica. Foram chamados de "áreas de exceção" ou “ilhas de umidades" em meio ao típico clima seco e quente da Caatinga no Agreste e Sertão nordestino. Nessas regiões, há milênios densamente povoada por seres humanos e animais, na parte montanhosa estão os denominados brejos de altitude, concentrando um maior índice anual de chuvas e fontes de água que possibilitam a lavoura de subsistência e para o comércio.

São nos brejos onde nascem riachos irrigando as áreas de pé-de-serra e alguns rios intermitentes que correm em direção ao Litoral. Nessas localidades também existiram pequenos engenhos, "engenhocas" para fabrico de rapadura e aguardente. E, em lugares disputados com antigos moradores vivendo da agricultura de subsistência e com o excedente para o comércio, ocorreu a instalação das fazendas de pecuária. Historicamente, a produção dos brejos vem abastecendo regularmente as feiras das cidades vizinhas e até das capitais.

A História Ambiental, a partir de uma abordagem interdisciplinar, busca estudar nos processos históricos as relações humanas com a Natureza. É um campo de pesquisas relativamente recente na área da História, embora as primeiras reflexões nessa perspectiva surgiram nos anos 1930, quando Marc Bloch, Lucien Febvre e Fernand Braudel, os chamados "pais fundadores" da École des Annales, iniciaram abordagens mais amplas e interdisciplinares nas reflexões históricas, tratado de temas sobre as relações humanas com a Natureza, a vida rural e o Mediterrâneo. Nos anos 1960/1970, diante das ameaças de um conflito nuclear mundial, as discussões ambientais foram retomadas.

Na década de 1970, surgiram nos Estados Unidos as primeiras discussões nomeadas como História Ambiental, sendo Donald Worster, professor na Universidade de Kansas, 
considerado um dos precursores da abordagem que rapidamente teve novos adeptos. No Brasil, autores como Euclides da Cunha, Sérgio Buarque de Holanda, Caio Prado Jr., Gilberto Freyre com o livro Nordeste, e Josué de Castro, com o livro Geografia da fome, são listados como "historiadores ambientais", embora não tenham explicitamente assumido tal perspectiva de abordagem.

Todavia, o livro A ferro e fogo: a história e a devastação da Mata Atlântica brasileira, do historiador norte-americano Warren Dean, publicado em 1996, é considerado como o marco das reflexões sistemáticas da História Ambiental em nosso país. Nas diferentes regiões do Brasil, vários historiadores vêm se dedicando à História Ambiental discutindo diversos temas sobre as relações humanas com o Ambiente, bem como as concepções que fundamentam a História Ambiental.

Em nossas reflexões, estamos propondo ampliar a perspectiva da História Ambiental para uma História Ambiental indígena no Semiárido, enquanto um exercício buscando estabelecer as relações entre os indígenas e as condições de vida no Ambiente ${ }^{17}$ onde habitam, ou seja, contribuindo para discussões na perspectiva histórica que evidenciem as relações de poder, nos acessos, utilizações e os significados dos recursos naturais para os povos indígenas Nessa proposta de abordagem, privilegiamos os grupos socialmente excluídos - no caso, os indígenas - nas suas interações com o Ambiente, o Semiárido nordestino.

\title{
História indígena no Semiárido pernambucano
}

No semiárido pernambucano,

\begin{abstract}
As serras, muito úmidas no inverno, não se prestam à pecuária e são aproveitadas por agricultores que cultivam cereais, plantas do ciclo vegetativo curto. Na estação seca, após a colheita do feijão, do milho e do algodão, o gado é levado para a serra, para o brejo, onde se mantém com este alimento suplementar à espera de que, com as primeiras chuvas, a caatinga reverdeça. São famosas por servirem de refrigério ao gado certas serras, como as de Jacarará, da Moça e de Ororobá, em Pernambuco. ${ }^{18}$
\end{abstract}

Com a lucrativa expansão da pecuária, mesmo as fazendas de algodão e os cafezais erradicaram seus plantios:

Para o proprietário, a partir de quando se tornou desinteressante ceder terras em parceria ou em arrendamento para pequenas lavouras, o que passou a interessar foi, sobretudo, o retorno das glebas cedidas cobertas com restos de culturas, para seus animais, ou com pastos plantados. ${ }^{19}$

Restava ao indígena pequeno agricultor na Serra do Ororubá em terras do antigo aldeamento de Cimbres, atualmente Pesqueira e Poção onde se localiza a Terra Indígena 
Xukuru do Ororubá, pequenas parcelas de terras, os chamados "sítios", insuficientes para a sua subsistência e da sua família ${ }^{20}$.

Um "Abaixo-assinado dos Índios da extinta Aldeia de Cimbres",21, contendo 192 assinaturas, foi enviado, em 1885, ao Presidente da Província de Pernambuco. Em um longo texto que antecede os nomes dos signatários, os índios apelaram para o senso de justiça da autoridade provincial, pedindo providências para "fazer cessar as perseguições de que são vítimas". Informavam que as terras públicas onde se encontravam estavam sendo invadidas por "verdadeiros intrusos". Os índios ocupavam-se "exclusivamente do trabalho da agricultura" para se manter e denunciavam as invasões das terras, por fazendeiros.

A exemplo de um fazendeiro que, fugindo da seca na Paraíba, ocupara uma das áreas mais férteis na Serra do Ororubá, com seu gado destruindo as roças dos indígenas que, por serem pobres, estavam sendo explorados e não eram ouvidos em suas queixas, pelas autoridades policiais,

Indivíduos sem título algum, entre eles, José Alexandre Correa de Mello, que vindo dos lados do cariri pela seca, apossou-se de um dos melhores sítios do extinto aldeamento, e ali tem fundado, por assim dizer, uma fazenda de gado, que cotidianamente destrói as lavouras dos suplicantes, que recorrendo à proteção legal, recorrendo às autoridades policiais não são atendidos, porque são desvalidos, são índios miseráveis, e como tais sujeitos a trabalharem como escravos para os ricos e poderosos!

Além da "linguagem" da exploração do trabalho indígena, os fazendeiros perseguiam os queixosos, que eram presos e processados. Como acontecera com Manoel Felix Santiago, o índio com o primeiro nome no abaixo-assinado, que, "por não ter cedido do seu direito" fora preso, mas absolvido:

Essa é a linguagem dos tais criadores da serra, que entendem levar os suplicantes a ferro e fogo, sendo que o primeiro dos abaixo assinados, por não ter cedido do seu direito, reclamando-o constantemente, foi preso, processado, e pronunciado como estelionatário, mas, felizmente absolvido pelo Juiz, que dá prova mais significativa da indignação da opinião pública, manifestada em seu favor.

Os índios afirmavam que, com a extinção do aldeamento, o Governo Imperial determinara "a demarcação dos terrenos que lhe eram pertencentes". Mas, embora tendo sido publicados os editais, pela Tesouraria da Fazenda, para propostas de agrimensores executores da medição, até aquela data a demarcação não fora reconhecida, sendo as terras invadidas por "intrusos", fazendeiros criadores de gado, destruidores das lavouras dos índios, "para que assim os suplicantes perseguidos abandonem as suas antigas e legítimas posses!"22

No citado documento, lembravam ainda os índios que Manoel Felix Santiago, superando "sérias dificuldades", fora "pessoalmente" procurar o Imperador, tendo sido 
orientado para se dirigir ao Ministro da Fazenda e este recomendara ao Presidente da Província tomar as providências necessárias para retirar os "intrusos" que invadiram as terras do antigo aldeamento. Afirmavam os signatários que cabia à autoridade provincial determinar ao Juiz Comissário da Comarca cumprir a "bem clara e terminante a disposição do Artigo $2^{\circ}$ da Lei número 601 de 18 de setembro de 50, que manda retirar os intrusos perdendo as benfeitorias etc." A referência relacionava-se ao previsto no citado artigo da Lei de Terras de 1850, para ocupações posteriores em terras demarcadas oficialmente. Embora esse não fosse, como afirmaram os índios no seu documento, o caso das terras do ex-aldeamento de Cimbres. Os índios encerravam o abaixo-assinado afirmando sua condição de "sempre prudentes, e respeitadores da lei"; demonstravam, assim, além do conhecimento da legislação em vigor, uma interpretação a favor deles, que garantisse a reivindicação de seus direitos.

A pesquisa documental demonstrou que a extinção oficial, em 1879, do antigo Aldeamento de Cimbres, consolidou o domínio dos fazendeiros, de longa data invasores nas terras férteis na Serra do Ororubá. Uma ou outra família indígena ficou com a propriedade de pequenos pedaços de terras, insuficientes para a sobrevivência. Os conflitos que se acentuaram após meados do Século XIX, mesmo depois da extinção do aldeamento, prolongaram-se por todo o século $\mathrm{XX}$, com fazendeiros invasores e a agroindústria de beneficiamento do tomate, de doces e leiteira instaladas em Pesqueira e ocupando as terras habitadas pelos indígenas e localidades próximas.

Na região do Sertão do São Francisco, o bioma predominante é a Caatinga, com uma vegetação baixa, arbustiva, espinhosa e resistente, adaptada à longos períodos de estiagem. Os brejos, os rios e as serras são os "oásis" no Sertão, e para acessá-los nos primeiros tempos da colonização foram abertos caminhos pela Caatinga em um trabalho difícil. Quando o gado era solto próximos nesses locais, ocorriam os conflitos com os moradores portugueses. $\mathrm{Na}$ perspectiva dos moradores, tais espaços serviam de "esconderijos" para os índios "errantes"23, "bravos" e "criminosos", que atacavam os povoados e as fazendas. Os colonizadores portugueses não compreendiam esses espaços como ambientes de uma tradição migratória própria dos índios.

No século XIX, intensificaram-se os embates entre índios e criadores de gado nas disputas pelo uso e o controle dos recursos naturais nas serras, brejos e ribeiras, locais com água para saciar a sede humana e dos animais. Esses conflitos expressaram as diferenças nas compreensões sobre a noção de território. Para os colonizadores, o território significava o espaço ocupado por homens capazes de desenvolvê-lo, legitimado pelo Estado por meio das leis e das instituições jurídico-administrativas impostas pelo sistema colonial. Para os índios 
no Sertão, as noções de território e de fronteiras eram fluídas em razão de suas mobilidades espaciais. $^{24}$

No mesmo período, existiam grupos não aldeados que resistiram à sedentarização, não se sujeitavam às ordens das autoridades locais e viviam em situações de conflitos permanentes com os criadores de gado. Foram chamados pelas autoridades e moradores brancos de índios "brabos", "bárbaros" ou "errantes". Alguns deles vivenciaram a experiência do aldeamento, o que não os impediu de continuarem a utilizar os seus espaços tradicionais de ocupação.

Na documentação da Diretoria dos Índios, disponível no Arquivo Público Estadual de Pernambuco, os Umã, os Pipipã, os Chocó e os Oê foram citados como os índios "brabos" responsáveis pelos ataques, roubos e mortes, apesar de muitos deles serem índios aldeados e batizados. Juntamente com o adjetivo de "bárbaros", esses índios também eram chamados de "rebeldes", pois não se sujeitavam as autoridades e eram acusados de promoverem a "desordem" pública com os ataques as fazendas. Os registros apontaram informações muito importantes sobre as disputas pelo acesso aos locais onde existia água potável. As longas estiagens e as secas que afligiam o Semiárido forçava os seres humanos e os animais buscarem as fontes de água fresca ${ }^{25}$.

O atual Sertão pernambucano faz parte das Caatingas semiáridas nordestinas, local de habitação da maioria dos povos indígenas no Nordeste. Dos atuais conhecidos 13 povos indígenas em Pernambuco, somente os Fulni-ô, os Xukuru do Ororubá e os Xukuru de Cimbres habitam o chamado Agreste. No Sertão estão os Atikum, Kambiwá, Kapinawá, Pipipã, Truká, Tuxá, Pankararu, Pankararu Entre Serras, Pankawiká, os Pankará na Serra do Arapuá e em Itacuruba. Esses povos indígenas habitam áreas de serras ou de influências serranas, como é o caso dos Atikum, em que a maior parte do seu território está localizado na Serra Umã; os Kambiwá e Pipipã habitam a região da Serra Negra e a Serra do Periquito. E ainda parte do território Kapinawá, localizado no interior da área de influência do Parque Nacional da Serra do Catimbau. Os Pankararu possuem parte de seu território em vales entre serras; os Pankará, na Serra do Arapuá ${ }^{26}$.

O povo indígena Pankará habita a Serra do Arapuá, um Brejo de Altitude, no município de Carnaubeira da Penha, no Sertão pernambucano, dentro do Bioma Caatinga, na Bacia do São Francisco. Este povo vem se mobilizando pelo direito à terra e por assistência governamental há mais de 50 anos, todavia, somente em 2003 se autodenominou como um dos "povos resistentes", reafirmando as mobilizações pela terra e a garantia de direitos sociais, como Saúde e Educação diferenciadas. Atualmente, o Território Pankará encontra-se 
em fase de finalização da demarcação das terras. Os Pankará afirmam também sua identidade por meio da ritualística do Toré ${ }^{27}$ com elementos da Natureza.

A Serra do Arapuá, em seus pontos mais altos, apresenta altitudes acima de 900 metros. Desde o início da colonização portuguesa, na região, foi registrada a ocupação dessa área por indígenas e negros africanos que foram escravizados, sendo um espaço de refúgio e moradia desses grupos ${ }^{28}$. O lugar vem sendo habitado pelos Pankará, por pequenos agricultores e alguns fazendeiros de médio porte. O Território Pankará, enquanto um brejo de altitude possui grande biodiversidade e é considerado um oásis no meio do Sertão circundante.

O antropólogo norte-americano William Hohenthal, visitou em 1952 a Serra Cacaria/Serra do Arapuá (atual Território Indígena Pankará), descrevendo-a como local favorável pela disponibilidade de recursos hídricos mesmo na estação seca, com evidências abundantes da presença permanente de indígenas, devido à quantidade de "cacos" e outros artefatos arqueológicos existentes naquele local ${ }^{29}$.

A presença indígena na Serra do Arapuá vem sendo reafirmada pelos indígenas, a partir de intrínsecas relações com o Ambiente, com o território e a noção de pertencimento por meio da expressão "Nasci no torrão da Serra". O “torrão", como também por ter nascido pelas mãos de uma parteira, "mãe e índia", dotada de conhecimentos religiosos, são evidências da união entre o ambiente físico e simbólico, na composição da identidade étnica diferenciada, quando expressa pela afirmação "tenho orgulho de ser Índio Pankará". 30

Os Pankará usam diversos recursos naturais para a sobrevivência, como por exemplo o Catolé, uma planta que não perde as folhas no período da estação seca. Trata-se de uma palmácea típica de regiões de encostas e de áreas drenadas da floresta semidecídua, mas também bem adaptável em outras áreas, como na Caatinga e no Cerrado brasileiro ${ }^{31}$. Essa planta é encontrada em diversas áreas na Serra do Arapuá e utilizada pelos Pankará para produção de artesanato, fabricação de diversos utensílios e para o consumo dos seus frutos.

Nas relações entre os Pankará e o Ambiente, a Serra do Arapuá é o "espaço físico e simbólico de ocupação tradicional e de representação identitária do grupo". ${ }^{32}$ Portanto, essa Serra compõe o espaço histórico e socioambiental para esses indígenas, pois suas atividades agrícolas de subsistência envolvem também práticas de sociabilidades e temporalidade por meio de um calendário próprio, demarcando o tempo de preparo da terra, plantio, colheita, as datas de festejos religiosos e de "retomadas" - conflitos vivenciados pelos Pankará com a sociedade envolvente. 
Os índios Pankará mantêm relações de "simbiose com os recursos naturais existentes na região" "33. Isto é, utilizam e dependem dos recursos naturais do seu território e, ao mesmo tempo, usam formas tradicionais de manejo da produção agrícola e da pecuária, que mantém a estabilidade e a preservação dos ecossistemas, colaborando com a conservação ambiental da Serra do Arapuá. Em relação às práticas agrícolas, predomina a técnica manual e o uso da enxada; plantam em áreas de potencial agricultável como o alto da Serra, em terras de potencial restrito ou ainda em áreas não indicadas para atividade agrícola, como é o caso das áreas de serrotes. Em relação às práticas de caça de animais silvestre, "A caça é presente na região e tem grande importância para o grupo [...]. Os caçadores nas aldeias têm grande importância social e são reconhecidos como homens "corajosos"”. 34

Os Pankará expressam diversos conhecimentos sobre o ambiente natural na Serra do Arapuá:

É importante destacar que o clima, o relevo e a hidrografia determinam e influenciam a produção agrícola e no tipo de vegetação natural das regiões naturais Pankará, como também na relação existente entre agricultura e pecuária. Pois nas regiões do agreste e chapadas os animais como caprinos, ovinos são criados amarrados e as galinhas no cercado, e geralmente estão sempre fortes. Nessas regiões não costumamos cercar as plantações. Já na região do sertão os animais são criados soltos e as roças cercadas. Além de caprinos, ovinos e suínos, existe também a criação de gado, embora em pequena quantidade, quem mais tem, possuem umas dez cabeças $[\ldots]^{35}$

Nessa perspectiva, a vida social deve ser analisada envolvendo questões socioculturais e ambientais, para entender como a Natureza foi/é apropriada pelos humanos, as formas dos processos de construção e reconstrução do ambiente natural e como o ser humano interfere nesse Ambiente e o Ambiente afeta a vida sociocultural. Historicamente, as relações estabelecidas entre os Pankará e a Serra do Arapuá ocorrem a partir das (des)continuidades desse grupo social em seu Ambiente, suas práticas de produtividade em nas relações e representações da/sobre a Natureza, em suas expressões socioculturais e cosmologia.

\section{Uma discussão em aberto}

As experiências vivenciadas pelos povos indígenas no Semiárido nordestino, constituem-se, portanto, em um desafio nas reflexões para a compreensão dos processos históricos que resultam nas mobilizações sociopolíticas atuais pelas reivindicações, conquistas e garantias de seus direitos. O exercício de reflexões sobre a construção sociocultural do ambiente natural, buscando evidenciar os percursos da História Ambiental e indígena seja entre os Pankará na Serra do Arapuá em Carnaubeira da Penha no Sertão, seja entre os Xukuru do Ororubá na Serra do Ororubá no Agreste em Pesqueira e Poção, ambas regiões no 
semiárido pernambucano, possibilitará compreendermos as afirmações identitárias dos povos indígenas em suas mobilizações sociopolíticas na História, nas semelhanças em diferentes processos e situações vivenciadas pelos índios no Semiárido do Nordeste do Brasil.

Pensar os povos indígenas no Semiárido nordestino, na perspectiva de uma História Ambiental e indígena, a exemplo dos estudos sobre os Pankará e os Xukuru do Ororubá, é realizar o exercício de pesquisas, análises e reflexões buscando estabelecer as relações entre esses grupos humanos e as condições de vida no Ambiente onde habitam, reconhecendo as sociodiversidades indígenas e contribuindo para discussões na perspectiva histórica que evidenciem as relações de poder, o acesso e a utilização de recursos naturais pelos povos indígenas, com a "redefinição do controle social sobre os recursos ambientais" 36 nas suas interações com o Ambiente no Semiárido nordestino.

\section{Notas}

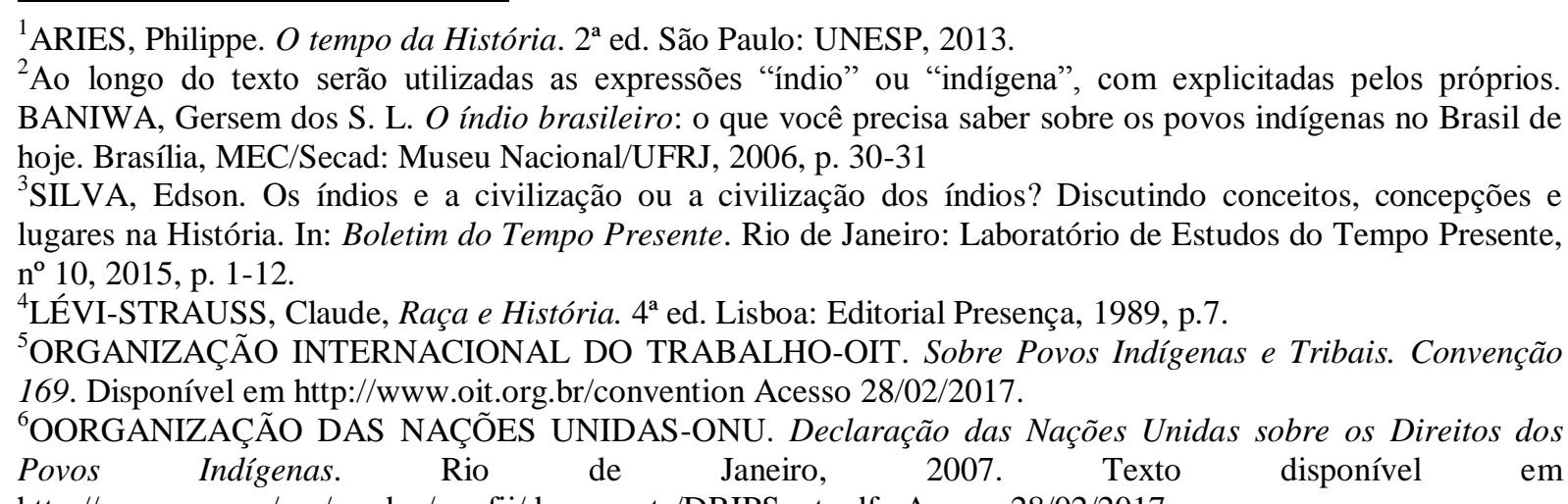

http://www.un.org/esa/socdev/unpfii/documents/DRIPS_pt.pdf Acesso 28/02/2017.
${ }_{7}$ OLIVEIRA, João Pacheco de. Trama histórica e mobilizações indígenas atuais: uma antropologia dos registros numéricos no Nordeste. In: OLIVEIRA, J. P. de. (Org.). A presença indígena no Nordeste: processos de territorialização, modos de reconhecimento e regimes de memória. Rio de Janeiro: Contra Capa, 2011, p.679.

${ }^{8}$ SILVA, Edson. Os povos indígenas e o ensino: possibilidades, desafios e impasses a partir da Lei 11.645/2008. In: FERREIRA, Gilberto G; SILVA, Edson H; BARBALHO, José I. S. (Orgs.). Educação e diversidade: um diálogo necessário na Educação Básica. Maceió: EDUFAL, 2015, p.161.

${ }^{9}$ OLIVEIRA, João Pacheco de. (Org.). A presença indígena no Nordeste: processos de territorialização, modos de reconhecimento e regimes de memória. Rio de Janeiro: Contra Capa, 2011; OLIVEIRA, João Pacheco de. (Org.). A viagem de volta: etnicidade, política e reelaboração cultural no Nordeste indígena. Rio de Janeiro: Contra Capa Livraria, 1999.

${ }^{10}$ SILVA, Edson H. Xukuru: memórias e história dos índios da Serra do Ororubá (Pesqueira/PE), 1950-1988. Tese Doutorado em História Social, Departamento de História/Instituto de Filosofia e Ciências Humanas, Universidade Estadual de Campinas, 2008.

${ }^{11}$ RIBEIRO, Darcy. Os índios e a civilização: a integração das populações indígenas no Brasil moderno. $4^{\mathrm{a}}$ ed. Petrópolis: Vozes, 1982. (A primeira edição brasileira foi publicada em 1970).

${ }^{12}$ Nesse período sob a orientação do antropólogo João Pacheco de Oliveira (UFRJ/Museu Nacional), pesquisadores iniciavam, a partir novas abordagens fundadas em outras concepções teóricas sobre identidade, Cultura e relações socioculturais, a elaboração de reflexões em dissertações e teses acadêmicas que evidenciavam a atuação sociopolítica dos índios no Nordeste nos processos históricos coloniais.

${ }^{13}$ RIBEIRO, Darcy. Sobre o óbvio. Rio de Janeiro: Guanabara, 1986, p. 248.

${ }^{14}$ ARRUTI, José Maurício P. A. Morte e vida do Nordeste indígena: a emergência étnica como fenômeno histórico regional. In: Estudos Históricos. Rio de Janeiro: UFF, v. 15, 1995, p. 54-94;

${ }^{15}$ BRASIL. Ministério da Integração Nacional. Nova delimitação do Semi-Árido brasileiro. Brasília/DF, 2005. 
${ }^{16}$ SILVA, Roberto Marinho A. da. Entre o combate à Seca e a convivência com o Semiárido: transições paradigmáticas e sustentabilidade do desenvolvimento. Tese de Doutorado, Desenvolvimento Sustentável/Política e Gestão Ambiental Brasília, Centro de Desenvolvimento Sustentável, Universidade de Brasília, Brasília, 2006, p.220

${ }^{17}$ A expressão "Ambiente" é usada pelos pesquisadores da História Ambiental em contraposição ao termo "meioambiente". A expressão "Ambiente", assim como "Natureza" representa uma ideia de totalidade onde o ser humano estar inserido em contínuas relações, embora como entes autônomos ao humanos. A esse respeito ver: WORSTER, D. Transformações da Terra: para uma perspectiva agroecológica na História. In: Ambiente \& Sociedade, vol. V, n. 2 - ago./dez. 2002, vol. VI, nº 1 - jan./jul. 2003; DUARTE, Regina Horta. História \& Natureza. Belo Horizonte: Autêntica, 2005; PÁDUA, José Augusto. As bases teóricas da História Ambiental. In: Estudos avançados, 24 (68), 2010, p.81-101.

${ }^{18}$ ANDRADE, Manoel Correia de. A terra e o homem do Nordeste. $6^{\mathrm{a}}$ ed. Recife: Edufpe, 1998, p. 157.

${ }^{19}$ ANDRADE, Manoel Correia de. A terra e o homem do Nordeste. $6^{\text {a }}$ ed. Recife: Edufpe, 1998, p.214.

${ }^{20}$ SILVA, Edson H. Xukuru: memórias e história dos índios da Serra do Ororubá (Pesqueira/PE), $1950-1988$.

Tese Doutorado em História Social, Departamento de História/Instituto de Filosofia e Ciências Humanas, Universidade Estadual de Campinas, 2008.

${ }^{21}$ Abaixo-assinado de índios da extinta Aldeia de Cimbres, em Pesqueira 25/02/1885, para o Presidente da Província. Arquivo Público Estadual de Pernambuco, Códice Petições, fls.18-23v.

${ }^{22}$ Abaixo-assinado de índios da extinta Aldeia de Cimbres, em Pesqueira 25/02/1885, para o Presidente da Província. Arquivo Público Estadual de Pernambuco, Códice Petições, fls.18-23v.

${ }^{23}$ ROSA, Hildo Leal da. A Serra Negra: refúgio dos últimos "bárbaros" do Sertão de Pernambuco. Monografia de Graduação, História, Departamento de História, Centro de Filosofia e Ciências Humanas, Universidade Federal de Pernambuco, Recife, 1988.

${ }^{24}$ SALDANHA, Suely Maris. Fronteiras dos sertões: conflitos e resistência indígena em Pernambuco na Época de Pombal. Dissertação de Mestrado em História, Departamento de História, Centro de Filosofia e Ciências Humanas, Universidade Federal de Pernambuco, Recife, 2002.

${ }^{25}$ SANTOS JÚNIOR. Carlos Fernando dos. Os índios nos Vales do Pajeú e São Francisco: historiografia, legislação, política indigenista e os povos indígenas no sertão de Pernambuco, 1801-1845. Dissertação de Mestrado em História, Departamento de História, Centro de Filosofia e Ciências Humanas, Universidade Federal de Pernambuco, Recife, 2015.

${ }^{26}$ PROENÇA, André Luiz. Ocupações pré-coloniais no Parque Nacional do Catimbau: proposta interpretativa às paisagens arqueológicas. Tese de Doutorado, Geografia, Departamento de Geografia, Centro de Filosofia e Ciências Humanas, Universidade Federal de Pernambuco, Recife, 2013.

${ }^{27} \mathrm{O}$ Toré é uma dança coletiva, ritual praticado pelos Pankará. É dançado ainda como diversão, uma "brincadeira" de índio. Mas, principalmente como forma de afirmação étnica dos povos indígenas no Nordeste em espaços públicos e mobilizações sociopolíticas. A esse respeito ver GRUNEWALD, Rodrigo de. Toré: regime encantado do índio do Nordeste. Recife: Fundaj/Massangana, 2005.

${ }^{28}$ SILVA. Luís Severino da. Brejos de altitude, refúgios para os grupos humanos do sertão: o caso da Serra do Arapuá, Floresta, PE. In: Clio Série Arqueológica, v.1, n. 14 - Anais da X Reunião Científica da SAB. Recife: UFPE, 1999, p. 237-244.

${ }^{29}$ MENDONÇA, Caroline L. Índios da Serra do Arapuá: identidade, território e conflito no Sertão de Pernambuco. Dissertação de Antropologia, Ciências Sociais, Departamento de Antropologia e Museologia, Centro de Filosofia e Ciências Humanas, Universidade Federal de Pernambuco, Recife, 2003.

${ }^{30}$ OLIVEIRA, Edivania Granja da Silva. Os índios Pankará na Serra do Arapuá: relações socioambientais no Sertão pernambucano. Dissertação de Mestrado em História, Unidade Acadêmica de História e Geografia, Centro de Humanidades, Campina Grande, 2014.

${ }^{31}$ CIRILO, José Almir. O uso sustentável dos recursos hídricos em regiões semiáridas. Recife, Edufpe, 2007

${ }^{32}$ MENDONÇA, Caroline Leal. (Org.). Nossa Serra, nossa terra: identidade e território tradicional Atikum e Pankará. Serra Umã e Arapuá. Conselho de Professores Indígenas Atikum e Organização da Educação Escolar Pankará - $\quad$ COPIPE, 2012. Disponível em: http://www.cimi.org.br/pub/publicacoes/Nossa\%20Serra\%20Nossa\%20Terra/nossa_serra_comclu.pdf. Acesso em 20/12/2013.

${ }^{33}$ BULCÃO, Luís Lyra da Silva. Relatório Ambiental: Grupo de Trabalho de Identificação/Delimitação da Terra Indígena da Serra do Arapuá. FUNAI - Salvaguarda de Comunidades Indígenas, Contrato $\mathrm{n}^{\circ}$ CLTO 1748/2009 e IRPF: AS-4043/2009, Florianópolis, 2010, p.41

${ }^{34}$ BULCÃO, Luís Lyra da Silva. Relatório Ambiental: Grupo de Trabalho de Identificação/Delimitação da Terra Indígena da Serra do Arapuá. FUNAI - Salvaguarda de Comunidades Indígenas, Contrato $\mathrm{n}^{\circ}$ CLTO 1748/2009 e IRPF: AS-4043/2009, Florianópolis, 2010, p.32. 


\begin{abstract}
${ }^{35}$ MENDONÇA, Caroline Leal. (Org.). Nossa Serra, nossa terra: identidade e território tradicional Atikum e Pankará. Serra Umã e Arapuá. Conselho de Professores Indígenas Atikum e Organização da Educação Escolar Pankará - COPIPE, 2012, p. 75-76. Disponível em: http://www.cimi.org.br/pub/publicacoes/Nossa\%20Serra\%20Nossa\%20Terra/nossa_serra_comclu.pdf. Acesso em 20/12/2013.

${ }^{36}$ OLIVEIRA, João Pacheco de. Uma etnologia dos "índios misturados": situação colonial, territorialização e fluxos culturais. In: OLIVEIRA, João Pacheco de. (Org.). In: A viagem de volta: etnicidade, política e reelaboração cultural no Nordeste indígena. Rio de Janeiro: Contra Capa, 2004, p. 13-38.
\end{abstract}

\title{
Referências bibliográficas
}

BRASIL. Instituto Brasileiro de Geografia e Estatística-IBGE. Censo 2010. http://censo2010.ibge.gov.br/resultados Acesso 28/02/2017.

ANDRADE, Manoel Correia de. A terra e o homem do Nordeste. $6^{\mathrm{a}}$ ed. Recife: Edufpe, 1998.

BRASIL. Ministério da Integração Nacional. Nova delimitação do Semi-Árido brasileiro. Brasília/DF, 2005.

BULCÃO, Luís Lyra da Silva. Relatório Ambiental: Grupo de Trabalho de Identificação/Delimitação da Terra Indígena da Serra do Arapuá. FUNAI - Salvaguarda de Comunidades Indígenas, Contrato $\mathrm{n}^{\circ}$ CLTO 1748/2009 e IRPF: AS-4043/2009, Florianópolis, 2010.

CASTRO, Josué de. Geografia da fome: o dilema brasileiro pão ou aço. $10^{\mathrm{a}}$ ed. Rio de Janeiro: Antares Achiamé, 1980.

CIRILO, José Almir. O uso sustentável dos recursos hídricos em regiões semiáridas. Recife, Edufpe, 2007.

DEAN, Warren. A ferro e fogo: a história e a devastação da Mata Atlântica brasileira. $1^{\mathrm{a}}$ ed. São Paulo: Cia. das Letras, 1996.

DUARTE, Regina Horta. História \& Natureza. Belo Horizonte: Autêntica, 2005.

FREVRE, Gilberto. Nordeste: aspectos da influência da cana sobre a vida e a paisagem do Nordeste do Brasil. Rio de Janeiro: José Olympio, 1967.

GRUNEWALD, Rodrigo de. Toré: regime encantado do índio do Nordeste. Recife: Fundaj/Massangana, 2005.

LINS, Rachel Caldas et alii. Áreas de exceção do Agreste de Pernambuco. SUDENE, Recife, 1989.

MENDONÇA, Caroline L. Índios da Serra do Arapuá: identidade, território e conflito no Sertão de Pernambuco. Dissertação de Antropologia, Ciências Sociais, Departamento de Antropologia e Museologia, Centro de Filosofia e Ciências Humanas, Universidade Federal de Pernambuco, Recife, 2003.

MENDONÇA, Caroline Leal. (Org.). Nossa Serra, nossa terra: identidade e território tradicional Atikum e Pankará. Serra Umã e Arapuá. Conselho de Professores Indígenas Atikum e Organização da Educação Escolar Pankará - COPIPE, 2012, p. 75-76. Disponível em:

http://www.cimi.org.br/pub/publicacoes/Nossa\%20Serra\%20Nossa\%20Terra/nossa_serra_ comclu.pdf. Acesso em 20/12/2013.

MELO, M. L. Os agrestes. Recife: SUDENE, 1980, p. 173-175.

MORGAN, Lewis H. A sociedade primitiva. Rio Janeiro: Martins Fontes, 1974 (Vol. I e II).

MONTEIRO, John Manuel. Tupis, Tapuias e historiadores: estudos de história indígena e de indigenismo. Tese de Livre-Docência, Antropologia, Departamento Ciências Sociais, Instituto de Filosofia e Ciências Humanas, Universidade Estadual de Campinas, Campinas, 2001. MONTEIRO, John Manuel. Redescobrindo os índios da América Portuguesa: 
Antropologia e História. In: AGUIAR, Odílio Alves; BATISTA, José Élcio; PINHEIRO, Joceny. (Orgs.). Olhares contemporâneos: cenas do mundo em discussão na universidade. Fortaleza: Edições Demócrito Rocha, 2001, p. 135-142;

MONTEIRO, John Manuel. Armas e armadilhas: História e resistência dos índios. In, NOVAES, Adauto. (Org.). A outra margem do Ocidente. São Paulo: Cia. das Letras, 1999, p. 237-249.

NUNES, Eduardo Soares. Aldeias urbanas ou cidades indígenas? Reflexões sobre índios e cidades. In: Revista Espaço Ameríndio. Porto Alegre: UFRGS, v. 4, n. 1, jan./jun. 2010, p. 90-30.

OLIVEIRA, Edivania Granja da Silva. Os índios Pankará na Serra do Arapuá: relações socioambientais no Sertão pernambucano. Dissertação de Mestrado em História, Unidade Acadêmica de História e Geografia, Centro de Humanidades, Campina Grande, 2014.

OLIVEIRA, João Pacheco de. Trama histórica e mobilizações indígenas atuais: uma antropologia dos registros numéricos no Nordeste. In: OLIVEIRA, J. P. de. (Org.). A presença indígena no Nordeste: processos de territorialização, modos de reconhecimento e regimes de memória. Rio de Janeiro: Contra Capa, 2011, p.653-687.

OLIVEIRA, J. P. de. (Org.). A presença indígena no Nordeste: processos de territorialização, modos de reconhecimento e regimes de memória. Rio de Janeiro: Contra Capa, 2011.

OLIVEIRA, João Pacheco de. (Org.). A viagem de volta: etnicidade, política e reelaboração cultural no Nordeste indígena. Rio de Janeiro: Contra Capa Livraria, 1999.

PÁDUA, José Augusto. As bases teóricas da História Ambiental. In: Estudos avançados, 24 (68), 2010, p.81-101.

PERES, Sidnei Clemente. Terras indígenas e ação indigenista no Nordeste (1910-1967). In: OLIVEIRA, João Pacheco de. (Org.). A viagem da volta: etnicidade, política e reelaboração cultural no Nordeste indígena. $2^{\mathrm{a}}$ ed. Rio de Janeiro: Contra Capa, 2004, p. 43 91.

PROENÇA, André Luiz. Ocupações pré-coloniais no Parque Nacional do Catimbau: proposta interpretativa às paisagens arqueológicas. Tese de Doutorado, Geografia, Departamento de Geografia, Centro de Filosofia e Ciências Humanas, Universidade Federal de Pernambuco, Recife, 2013.

RAFFESTIN, Claude. Por uma Geografia do poder. São Paulo: Ática, 1993.

RIBEIRO, Darcy. Os índios e a civilização: a integração das populações indígenas no Brasil moderno. $4^{\mathrm{a}}$ ed. Petrópolis: Vozes, 1982. (A primeira edição brasileira foi publicada em 1970).

RIBEIRO, Darcy. O povo brasileiro: a formação e o sentido do Brasil. $2^{\text {a }}$ ed. São Paulo: Cia. das Letras, 1995.

ROSA, Hildo Leal da. A Serra Negra: refúgio dos últimos "bárbaros" do Sertão de Pernambuco. Monografia de Graduação, História, Departamento de História, Centro de Filosofia e Ciências Humanas, Universidade Federal de Pernambuco, Recife, 1988.

SANTOS JÚNIOR. Carlos Fernando dos. Os índios nos Vales do Pajeú e São Francisco: historiografia, legislação, política indigenista e os povos indígenas no sertão de Pernambuco, 1801-1845. Dissertação de Mestrado em História, Departamento de História, Centro de Filosofia e Ciências Humanas, Universidade Federal de Pernambuco, Recife, 2015.

SILVA, Edson H; SANTOS, Carlos A. Batista; OLIVEIRA, Edivania G. da Silva; COSTA NETO, Eraldo M. (Orgs.). História Ambiental e história indígena no Semiárido brasileiro. Feira de Santana: UEFS, 2017. 
SILVA, Edson H; SANTOS, Carlos A. Batista; OLIVEIRA, Edivania Granja da S. (Orgs.). História Ambiental: recursos naturais e povos tradicionais no Semiárido nordestino. Curitiba: Appris, 2017.

SILVA, Edson; OLIVEIRA, Edivania G. da S; SANTOS JR. Carlos F. dos. Os povos indígenas no "sertão verde": mobilizações, conflitos e afirmações identitárias no semiárido pernambucano. In: $O$ encolhimento das águas: o que se vê e o que se diz sobre a crise hídrica e a convivência com o Semiárido. Campina Grande: INSA, 2017, p. 33-58.

SILVA, Edson. Os povos indígenas e o ensino: possibilidades, desafios e impasses a partir da Lei 11.645/2008. In: FERREIRA, Gilberto G; SILVA, Edson H; BARBALHO, José I. S. (Orgs.). Educação e diversidade: um diálogo necessário na Educação Básica. Maceió: EDUFAL, 2015, p.161-180.

SILVA, Edson. Xukuru: a conquista do Posto. O início da atuação do SPI entre os Xukuru do Ororubá (Pesqueira-PE). In: FREIRE, Carlos Augusto da Rocha (Org.). Memória do SPI: textos, imagens e documentos sobre o Serviço de Proteção aos Índios (1910-1967). Rio de Janeiro: Museu do Índio/FUNAI, 2012, p. 274-283.

SILVA, Edson H. Xukuru: memórias e história dos índios da Serra do Ororubá (Pesqueira/PE), 1950-1988. Tese Doutorado em História Social, Departamento de História/Instituto de Filosofia e Ciências Humanas, Universidade Estadual de Campinas, 2008.

SILVA, Edson. "Os caboclos" que são índios: história indígena no Nordeste. In: Portal do São Francisco. Belém de São Francisco: CESVASF, v. 3, 2004, p. 127-137.

SILVA, Edson. Povos indígenas no Nordeste: contribuição à reflexão histórica sobre o processo de emergência étnica. In: Mneme. Caicó: UFRN, v. 4, n.7, fev./mar. 2003, p.3645.

SILVA. Luís Severino da. Brejos de altitude, refúgios para os grupos humanos do sertão: o caso da Serra do Arapuá, Floresta, PE. In: Clio Série Arqueológica, v.1, n. 14 - Anais da X Reunião Científica da SAB. Recife: UFPE, 1999, p. 237-244.

VASCONCELOS SOBRINHO, João de. As regiões naturais de Pernambuco, o meio e a civilização. Recife: Condepe, 2005.

WORSTER, D. Transformações da Terra: para uma perspectiva agroecológica na História. In: Ambiente \& Sociedade, vol. V, n. 2 - ago./dez. 2002, vol. VI, nº 1 - jan./jul. 2003. 